\title{
PREDICTION OF CAR CABIN ENVIRONMENT BY MEANS OF 1D AND 3D CABIN MODEL
}

\author{
Fišer J.*, Pokorný J.* ,Jícha M.*•
}

\begin{abstract}
:
Thermal comfort and also reduction of energy requirements of air-conditioning system in vehicle cabins are currently very intensively investigated and up-to-date issues. The article deals with two approaches of modelling of car cabin environment; the first model was created in simulation language Modelica (typical 1D approach without cabin geometry) and the second one was created in specialized software Theseus-FE (3D approach with cabin geometry). Performance and capabilities of this tools are demonstrated on the example of the car cabin and the results from simulations are compared with the results from the real car cabin climate chamber measurements.
\end{abstract}

\section{INTRODUCTION}

Thermal comfort and indoor environment with nonhazardous concentrations of pollutants are two basic conditions for the overall comfort. Thermal comfort also affects performance of man during mentally challenging activities such as driving of vehicles (e.g. cars). Studies in recent years $[1,2]$ reveals, that with decreasing of thermal comfort and insufficient ventilation of a car cabin, the driver's vigilance drops and the drivers response time increases. Nowadays, thermal comfort and sufficient ventilation of the cabin under all operating conditions are basic requirements of most car manufacturers in the development phase of a new model or series of cars. During design and construction phase of the new air conditioning pack, the requirements on fuel consumption and regulations for undesirable substances emissions (e.g. carbon dioxide) also come into play. Producers are therefore forced to find a new ways and methods for cabin environment conditioning with the minimal power consumption. One type of the software tools, which enables testing of the effects of cabin materials and air-conditioning system modifications during the development phase are 1D simulation software tools discussed in this article. The main goal of the work was to create a VW Polo cabin model which is designed for verification of the effects of various cabin modifications onto energy balance of the cabin and the air conditioning system. Authors selected two different types of 1D approach; the first - 1D model without cabin geometry implemented in Modelica language Modelica and the second one - 1D model with 3D cabin geometry created in specialized software Theseus-FE.

\footnotetext{
- Ing. Jan Fišer, Ing. Jan Pokorný, prof. Ing. Miroslav Jícha CSc., Brno University of Technology, Faculty of Mechanical Engineering, Technická 2, 61669, fiser@fme.vutbr.cz, ypokor25@stud.fme.vutbr.cz, jicha@fme.vutbr.cz, (+420) 54114 3242, (+420) 541143264 , $(+420) 541143271$
}

This is an Open Access article distributed under the terms of the Creative Commons Attribution License 2.0, which permits unrestricted use, distribution, and reproduction in any medium, provided the original work is properly cited. 


\section{Cabin enviRonment Simulation by 1D APPROACH}

This model describes the cabin without considering any geometry only surface areas. Model was implemented in Openmodelica language (by using Simforge) but after the implementation, the model was transcript to Modelica language (Openmodelica is open source solution of Modelica and they are almost the same). Despite the model is quite simple, it includes many parameters describing material properties and surface areas of the cabin. Only cabin and trunk exterior surfaces were taken into account (not space for engine). Exterior surfaces were divided into glass and metal ones and interior was considered as one node containing seats, dashboard, etc.. Effective areas of interior objects and inner surface of outer envelope were considered as well. The cabin was divided into 3 nodes: exterior surfaces, interior surfaces and air in the cabin. Three heat balance equations and one mass balance of moisture in air zone were created; moreover the total heat balance of cabin was established. Altogether the model counts 5 equations. For example, equation for heat balance in the air zone node is

$$
\frac{d T_{\text {airz }}}{d t} \cdot m_{\text {airz }} \cdot c_{\text {airz }}=-Q_{\text {conv }}+\frac{d m}{d t} \cdot\left(i_{\text {air }, k}-i_{\text {airz }}\right)-m_{\text {airz }} \cdot \frac{d x}{d t} \cdot \frac{d i_{\text {airz }}}{d x}[W]
$$

In Figure 1, there is shown heat transfer of the model; the arrows show the heat exchanges between nodes, which are based on the heat transfer principles represented here by chars: R - radiation, S - solar radiation, RS - reflected solar radiation, $\mathrm{C}$ - convection, $\mathrm{K}$ - conduction. The model does not calculate temperature changes in surroundings and in HVAC system - this data are take into account as inputs of model

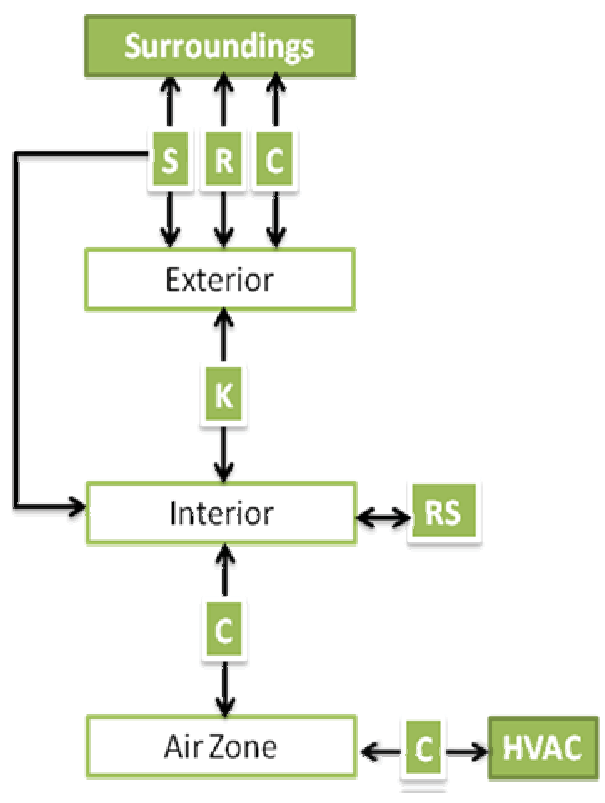

\begin{tabular}{|c|l|}
\hline \multicolumn{2}{|l|}{ Where } \\
\hline R & Radiation heat transfer \\
\hline S & Solar radiation heat transfer \\
\hline RS & $\begin{array}{l}\text { Reflected solar radiation } \\
\text { heat transfer }\end{array}$ \\
\hline C & Convection heat transfer \\
\hline K & $\begin{array}{l}\text { Conduction between outer } \\
\text { (exterior) and inner } \\
\text { surfaces (interior) }\end{array}$ \\
\hline
\end{tabular}

Figure 1 Heat transfer scheme - 1D cabin in Modelica language

\section{Cabin environment Simulation by 3D approach}

The 3D model was created in the software Theseus-FE 3.0. Detailed CAD model of the car cabin has been simplified and there were left only the essential surfaces forming the cabin and its interior. Relevant materials, for individual surfaces, were defined either 
single or multilayer. The interior was divided into left and right side, while each side was divided into the six zones/volumes (see Figure 2) plus Zones 1 and 4, which were not laterally divided. Thus three separated zones for each seat were created, representing the head space (e.g. Z 2-L), body space (e.g. Z8-L) and space for legs (e.g. Z7-L). Flows between the zones (so-called advection scheme) were defined (see Figure 3), and described the volumetric flows of air in the directions from, within and between zones. By this way it is possible to create the flow pattern corresponding to the real flow pattern, but it should be noted that the shape of the pattern is very strong influenced by mode of ventilation, and thus the pattern shape can vary very considerably. Therefore for each test cases it is necessary to redefine volume flow settings between the zones, which is very complicated and time consuming.

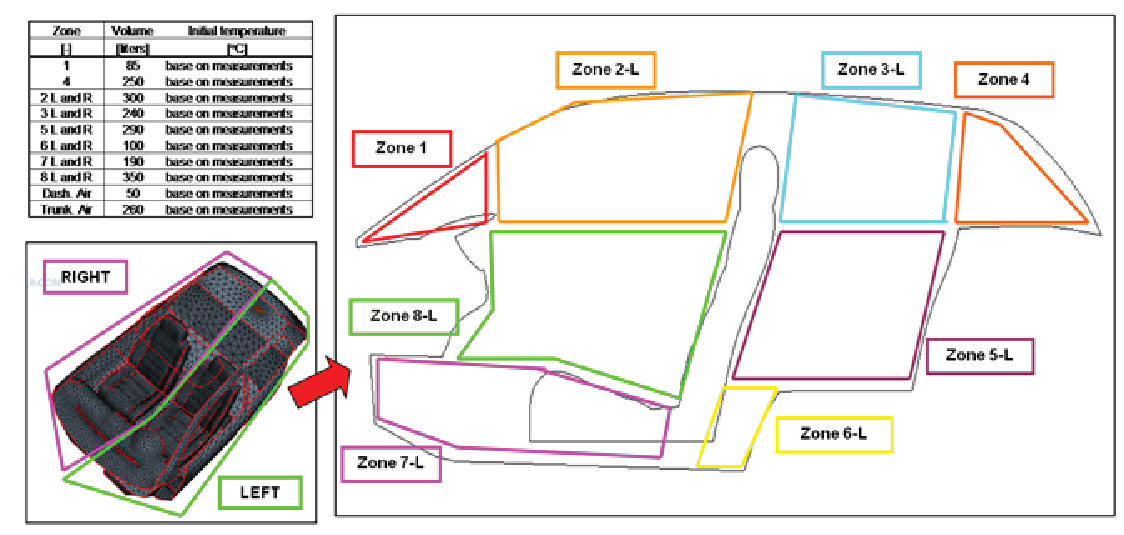

Figure 2 Cabin interior - air zones definitions

Convective heat transfer between surface and air (in each zones, to the ambient air) was solved by empirical equations, which are selected according to the expected predominant type of convection (natural/forced/ mixed). The air velocity and temperature difference between surface and air in the adjacent zone are inputs into these equations. For the external part of the car body and glasses it was used the forced convection equation and inside the cabin there were used equations for forced convection and mixed convection.
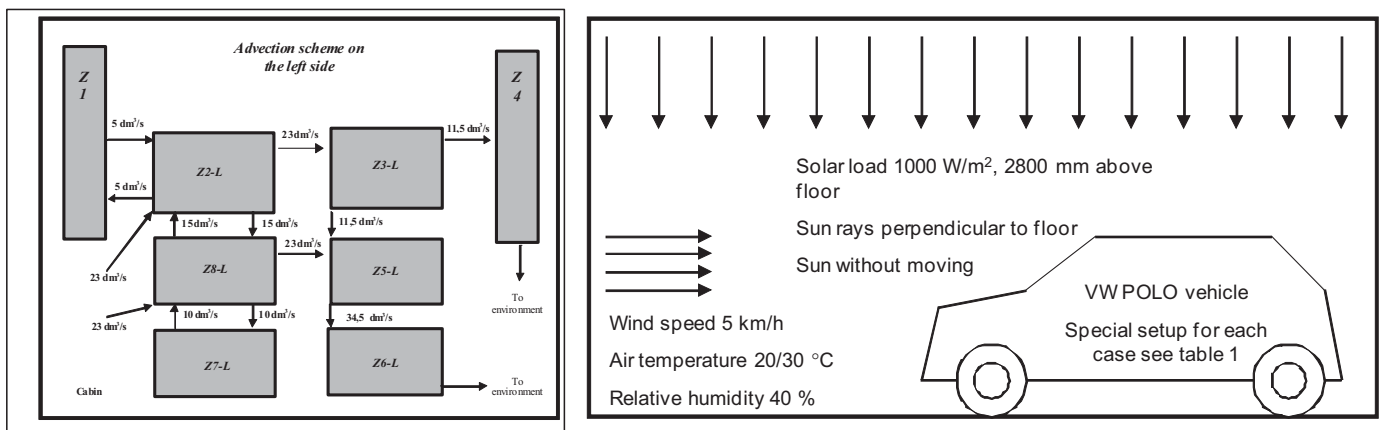

Figure 3 Advection scheme in the car cabin in case of cooling by air conditioning during a hot summer day, and setting of the environment boundary conditions

Boundary conditions of the ambient environment are shown in Figure 3, on the right. They are based on measurements of real Volkswagen Polo in climatic chamber, where environment conditions were equal to a very hot summer day. Sun lamps forming the artificial sun were placed on the ceiling of the climatic chamber and they generated the short-wave radiation of $1000 \mathrm{~W} / \mathrm{m}^{2}$ intensity. Car speed was simulated by speed of 
airflow, which was equal to $32 \mathrm{~km} / \mathrm{h}$ for the period of $3600 \mathrm{~s}$ and then decreased to 6 $\mathrm{km} / \mathrm{h}$ for a rest of measurement $(1800 \mathrm{~s})$. The ambient air temperature was maintained at $43{ }^{\circ} \mathrm{C}$ and relative humidity at $40 \%$. Air for ventilation was supplied to the car cabin from the main dashboard outlets only with the total mass flow $0.107 \mathrm{~kg} / \mathrm{s}$. The air temperature depends on the time of the simulation (see Fig. 4, left).

\section{Discussion OF RESULTS}

The results obtained from simulation and measurement are shown in Figures 4 to 6 . The temperatures of air entering the cabin (blue curves) and air temperatures in each zone (other curves) obtained from measurements are shown in Figure 4 - on the left. The curve of the air temperature in the driver's head space (dark purple) has the different shape compared to the curve of the air temperature in the co-driver head space (light green). This is in sharp contrast to the patterns in the other zones, where the patterns are very similar for the zones with the same positions (e.g. zone Z3-L and Z3-P). Hence air temperature data fromof driver head space was excluded from next results comparison. Comparison of average air temperature in the cabin for the measurement and both simulation models is shown in Figure 4, on the right. At the beginning of the cool down process the decline of the average temperature in the 3D model is faster than in the real cabin (the higher discrepancy up to $4{ }^{\circ} \mathrm{C}$ ) and also the temperature after the decrease of speed from 32 to $6 \mathrm{~km} / \mathrm{h}$ is again rise up faster in the 3D model (the higher discrepancy up to $2^{\circ} \mathrm{C}$ ). This differences are probably caused by the simplifications in the model (shape, heat capacity and mass of the model), due to the discrepancies and simplifications of initial boundary conditions setup and also due to the simplified simulation of the airflow in the cabin. On the other hand results from Modelica 1D simulation model fitted the data from measurements very well. The reason for that is the fact, that model parameters were optimized and the measured case was good for 1D model approach.
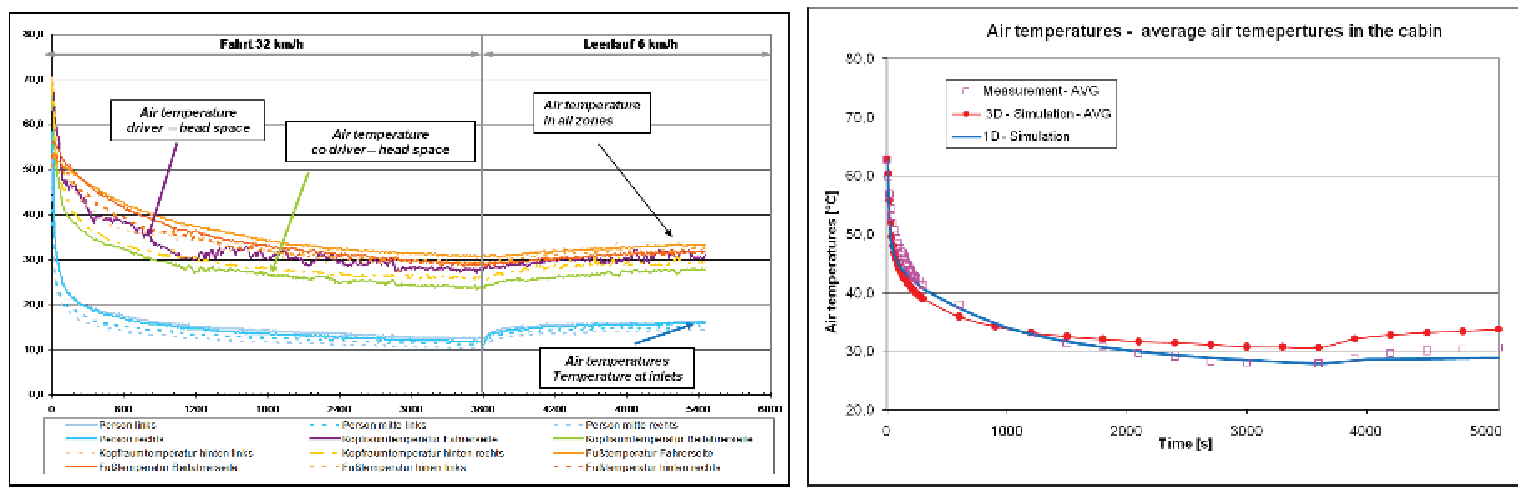

Figure 4 Air temperature (measurement) in each air zones vs. time (on the left) and comparison of the average air temperature from measurement and simulation for the entire cabin (on the right)

In the Figure 5, there is shown the distribution of surface temperatures in 3D model for the beginning and the end of the simulation. At the beginning it was set uniform temperature on each boundary condition as the initial condition, and therefore the distribution of temperatures is very uniform for most parts of the interior. Temperature distribution at the end of the simulation (Figure 5 - on the right) illustrates completely the capabilities and benefits of the 3D geometry for calculation of the heat transfer by radiation. It can be seen that the influence of shading, the result of impact of solar 
radiation on various surfaces (dashboard, seats, trunk cover) and also the influence of transmitted solar radiation which coming through the dark transparent roof window and impacting to the front seats (region with higher temperature on the front seats). The interior temperature and the air temperatures in the cabin are relatively high, but it has to be noted that the measurement and the simulation was performed under climate conditions of a very hot summer day.
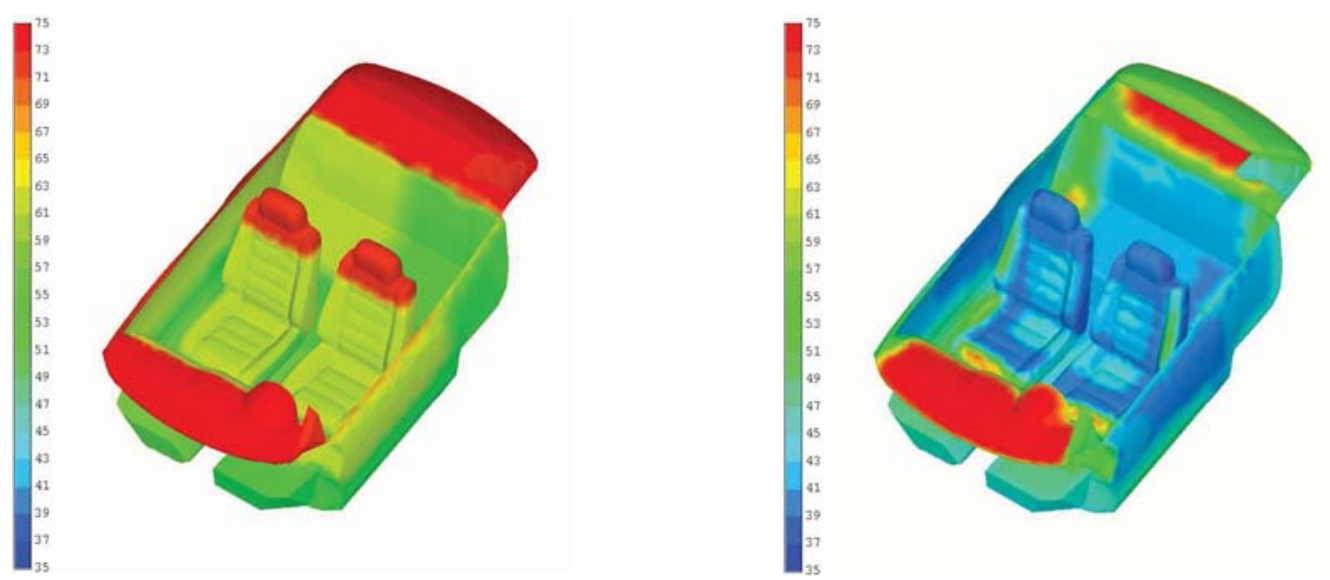

Figure 5 Temperatures distribution - interior surfaces: time 0s (on the left) and at 5400s (on the right)

In figure 6, there is shown the overall heat flow (solid line) which is defined as a sum of heat flows from environment (dotted line) and from HVAC system (dashed line) into the cabin. The negative values mean that the heat leaves the cabin, and the positive values mean that the heat enters the cabin. So from the figure 6 can be seen that the cabin is still losing the heat. Until the time $1260 \mathrm{~s}$ the surroundings cools the cabin (dotted line is negative), but thereafter the situation starts to be opposite. Also the air temperature in cabin is more and more close to the HVAC temperature, thus the cooling power of HVAC system decreases. Most important result which can be seen in figure 6 is that the heat balance state of the cabin is reached after $4000 \mathrm{~s}$, when the overall heat flow (solid line) is approaching to the zero.

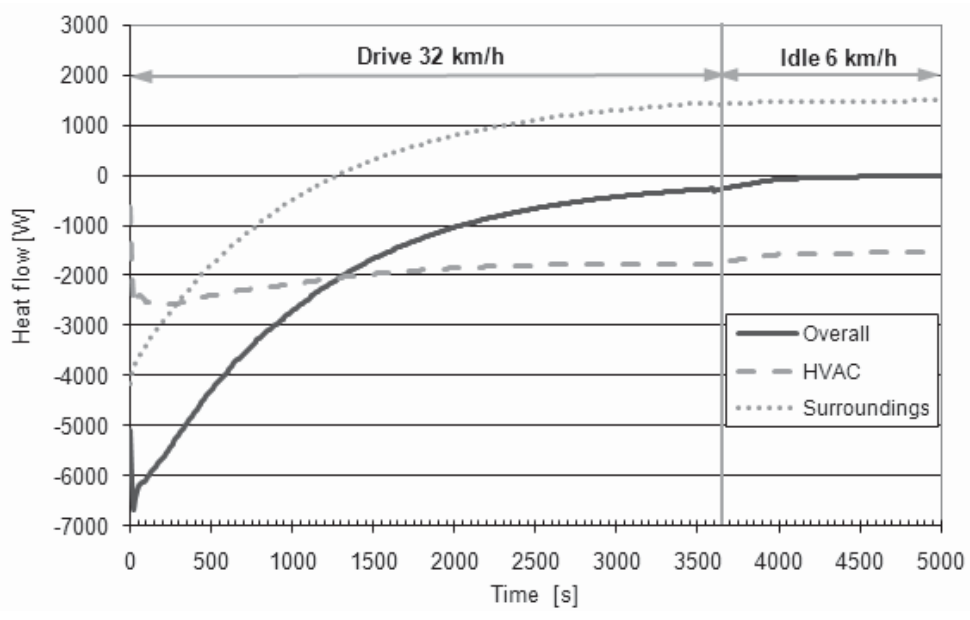

Figure 6 Heat flow in 1D Modelica model time from 0s till 5400s 


\section{Conclusions}

The models of VW Polo cabin created in Modelica language and in the 1D specialized simulation software Theseus FE 3.0 were presented in the article. The aim of the work was to developed the model of the cabin for verification of impacts of the cabin modifications to the cabin environment and air conditioning system energy consumption. The models were validated with the results from measurements of the real car cabin in the climate chamber for simulated climate conditions of a very hot summer day. The results from the simulations and measurement are in good agreement and discrepancies are relatively low. We can concluded that 1D approach for cabin environment simulations is suitable for transient simulations with duration of hours, whereas time cost of computation stay in order of tens of minutes. The greatest weakness of the 1D approach with 3D geometry, is the fact, that the air flow between the zones (so-called the advection scheme) is set manually and also the code of software is closed thus some parameters of the model cannot be controled. It may leads to the incorrect settings and decreases the precision of the simulation. On the other hand 1D approach with Modelica language model showed that 1D geometry less approach is very promising method for cabin environment simulations. Although the method does not provides detailed information about surface temperatures, it's extremely low time cost of computation (one hour of simulated time costs approximately 1 minute of CPU time) and good correlation of prediction with real data are main advantages, which favour model in Modelica for the next cabin model development.

Acknowledgements: This article was supported by the project BD13001007 Complex modelling of interaction of the cabin indoor environment and health hazards. Technical support and consultations from Volkswagen company are also gratefully acknowledge.

\section{REFERENCES}

[1] Huang, K. D. \& Tzeng, S. \& Jeng, T. \& Chiang, W. Air-conditioning system of an intelligent vehicle-cabin, Applied Energy, Volume 83, Issue 6, June 2006, s. 545557, ISSN 0306-2619

[2] Norin, F. \& Wyon, D. Driver Vigilance: the Effects of Compartment Temperature, SAE paper $n$. 920168, SAE international, 1992 